\title{
INTELIGENCIA EMOCIONAL Y ÉTICA DE LA RESPONSABILIDAD SOLIDARIA: COMO CONTRIBUIR HOY A UNA PEDAGOGÍA HUMANIZADA
}

\section{EMOTIONAL INTELLIGENCE AND ETHICS OF SOLIDARITY-BASED RESPONSIBILITY: HOW TO CONTRIBUTE TODAY TO PEDAGOGY}

\author{
María del Carmen Patricia Morales'. Universidad de Lovaina. Bélgica. \\ patricia.morales@kuleuven.be
}

\section{RESUMEN}

El fin de este trabajo es contribuir en el proceso educativo de los niños y jóvenes desde la inteligencia emocional y el consenso de principios éticos universales. Se recurre a un enfoque transdisciplinario que reúne tres fuentes diversas, pero convergentes: la propuesta de Goleman del paradigma de inteligencia emocional, que parte de la filosofía y de la psicología experimental; la ética de la corresponsabilidad solidaria elaborada como complemento de la ética discursiva de Karl-Otto Apel, y a ello se suma el marco normativo del derecho internacional y de las Naciones Unidas, en particular, la Convención de los Derechos del Niño. Finalmente, y teniendo en cuenta la situación dada por la pandemia de la COVID19 se ofrecen algunas reflexiones finales sobre la importancia y conveniencia de una propuesta transdisciplinaria y transcultural, que permite una comprensión que parte de lo local hasta lo planetario.

Palabras clave: Inteligencia emocional, ética de la responsabilidad, solidaridad, derechos humanos universales, educación de valores

\begin{abstract}
The purpose of this work is to contribute to the educational process of children and young people from emotional intelligence and the consensus of universal ethical principles. A transdisciplinary approach is used that brings together three diverse but convergent sources: Goleman's proposal of the paradigm of emotional intelligence, which starts from philosophy and experimental psychology; the ethics of joint responsibility jointly developed as a complement to Karl-Otto Apel's discursive ethics, and to this is added the normative framework of international law and the United Nations, in particular, the Convention on the Rights of the Child. Finally, and taking into account the situation given by the COVID19 pandemic, some final reflections are offered on the importance and convenience of a transdisciplinary and cross-cultural proposal, which allows an understanding that starts from the local to the planetary.
\end{abstract}

\section{Keywords:}

Emotional intelligence, ethics of responsibility, solidarity, universal human rights, education of values.

\footnotetext{
${ }^{1}$ María del Carmen Patricia Morales: Profesora invitada de la Universidad de Lovaina. Doctora en filosofía por la Universidad de Buenos Aires en cooperación con la Universidad Goethe, Frankfurt. Se dedica a temas de ética, derechos y responsabilidades humanos, y filosofía iberoamericana. Es periodista y escritora.
} 


\section{Cómo citar el artículo:}

Morales, M. del C. P. (2020). Inteligencia emocional y ética de la responsabilidad solidaria: como contribuir hoy a una pedagogía humanizada. Revista de Ciencias de la Comunicación e Información, 25(2), 55-70. doi: http://doi.org/10.35742/rcci.2020.25(2).55-70

\section{INTRODUCCIÓN²}

La inteligencia emocional ha propuesto una alternativa fructífera (tal como apunta Suberviola, 2012) y ha redefinido el concepto de inteligencia (Niño et ál., 2017), ante al paradigma dominante de categorizar a las personas según su coeficiente intelectual, lo cual no termina siendo de beneficio al ser humano ni a su medio social. Esta última encumbraría los talentos propios de las destrezas intelectuales, dejando al azar el control de las emociones y sentimientos. Pero las ideas tienen valor en el cambio social (Arroyo, 2013). Con la inteligencia emocional se piensa más allá de ello, gestionándolos. Barrientos (2019) define la inteligencia emocional (IE) como la capacidad de controlar y gestionar positivamente las emociones propias y ajenas, en un escenario cualquiera, donde se producen experiencias y cambios como parte del proceso de aprendizaje personal.

Por su parte el pensar ético trasciende la racionalidad calculadora, con conceptos como el de la Innovación responsable (Fernández-Beltrán et ál, 2017) y se esfuerza por repensar la condición humana a partir del obrar bien, desde un respeto de los derechos humanos comprendidos en su universalidad a partir de reconocer la dignidad humana, una suerte de línea humanista que se nutre del pensamiento humanista a partir del holocausto, y que podemos encarnar en la Declaración Universal de Derechos Humanos y la subsiguiente evolución hasta la fecha. Ambas son dos respuestas alentadoras para crisis actuales de la humanidad. Se trata aquí de una convergencia (Maliandi) de ambas para así ofrecer ciertas claves que puedan hacer frente a desafíos urgentes del siglo XXI que nos concierne como familia humana, como son los escenarios tratados por Bustos et ál. (2019) o Catalina-García et ál. (2019) y las consideraciones docentes de Abanades (2016) matizadas por las observaciones pertinentes de Carreras (2014) y Teruel (2014), por cuanto en tanto El empleo ascendente y masivo de la tecnología está íntimamente relacionado con la educación y la formación de capacidades, destrezas y habilidades en la población (Ganga y Luna, 2018).

\section{OBJETIVOS}

Contribuir a la consolidación de una pedagogía que promueva una aptitud ética hacia sí mismo, los demás y que contenga una perspectiva ciudadana que pueda tener una visión amplia, desde lo local a lo global.

\footnotetext{
2 Ante todo, deseo agradecer a mi antigua colega de la Universidad de Lovaina, la profesora Almudena Barrientos por esta invitación para tratar el tema de la inteligencia emocional desde un contexto de la ética.
} 
Establecer un proceso de colaboración entre los hallazgos de la inteligencia emocional de Goleman y la ética de la responsabilidad solidaria de Karl-Otto Apel y el marco normativo de las Naciones Unidas y de sus agencias, como la UNESCO.

Ayudar a consolidar una propuesta que logre complementar los hallazgos de la inteligencia emocional, la ética discursiva de la responsabilidad solidaria y la universalidad de la educación y los derechos humanos.

Hacer una propuesta integradora de pedagogía accesible e inter/transcultural, que tiene en cuenta tanto la formación personal como ciudadana a partir de los aportes de la filosofía a lo largo de la historia para promover la libertad y su correlato, la responsabilidad.

Integrar esta pedagogía ético-ciudadana en el marco de las formulaciones de Naciones Unidas, en particular, la Convención de los Derechos del Niño, la educación como practica para la libertad de la UNESCO y la Agenda 21.

\section{METODOLOGÍA}

Para esta propuesta transdisciplinaria que pueda consolidar una pedagogía que promueva el desarrollo de una aptitud ética tal como la aquí propuesta, se recurre a un estudio comparativo que pone en diálogo elementos constitutivos de la psicología de Goleman, la filosofía de Karl-Otto Apel y la normatividad evolutiva de las Naciones Unidas sobre derechos humanos, y procura lograr una complementariedad entre las diversas disciplinas.

En primer lugar, se trata de determinar los aspectos novedosos y el impacto del nuevo paradigma de Goleman, que trae una perspectiva liberadora en el campo pedagógica frente al desgastante criterio del coeficiente intelectual. Se estudian los ejemplos ad hoc para ese cambio de paradigma, la influencia de la ética aristotélica, y la relación empatía y ética, viendo allí ciertas limitaciones.

Se recurre, en segundo lugar, a explicar la propuesta filosófica de una ética global, fruto de la herencia griega en común con Goleman, a la cual se ha podido enriquecer gracias al universalismo kantiano y la intersubjetividad de la ética discursiva.

En tercer lugar, se considera el marco jurídico ofrecido por las Naciones Unidas, como elemento necesario para histórica y culturalmente poder detectar un componente esencial para lograr una pedagogía que pueda combinar los aspectos individuales y universales atendiendo a la formación ética de los jóvenes de una forma abarcadora, no solo individual, sino dando claves de solidaridad mundial.

El examen comparativo de estos tres recursos va a permitir detectar la mejor forma de complementarlos. Se estudiará cada elemento constitutivo, viendo su aporte, su impacto, y además sus limitaciones. Temas como el contexto histórico, social, político van a ser tenidos en cuenta para poder hacer una propuesta totalizadora, en que las tres fuentes puedan dar lugar a una pedagogía que pueda promover una visión y acción enmarca en una ética de libertad y responsabilidad. 


\section{DISCUSIÓN}

\subsection{El paradigma de la inteligencia emocional de la psicología de Goleman}

Goleman en su libro, La inteligencia emocional (2000), desde un maremágnum de definiciones (Martínez-Otero y García-Lago, 2013) propone una alternativa humanizada a aquella forma contemporánea dominante de comprender a la inteligencia humana en razón de la medición por coeficiente intelectual (IQ). Esta dimensión de la razón se había adueñado de los espacios educativos y laborales, creando políticas de exclusión, frustración y aislamiento, y fomentándose de ese modo relaciones sociales de abrupta competencia y violencia. El espacio público quedaba guiado por criterios de selección que realimentan ideologías neodarwinianas, que siguen a ciegas un modelo competitivo destructivo que termina en muchos casos con la integridad de las personas y la cohesión comunitaria.

A través del examen exhaustivo de casos de la psicología, Goleman logra mostrar que este enseñoramiento de una política basada en el IQ lo que hace es hacer retroceder el desarrollo de una buena gestión de emociones y sentimientos, para lo cual propone pensar desde la óptica de lo que él da en llamar inteligencia emocional. Según Goleman (2000), no basta tener la máxima destreza teórica intelectual, si con ello no se logra el buen dominio de las propias emociones. Para comprender el significado de su propuesta podemos recurrir a "impotens" que es una palabra latina que significaba no tener una potencia determinada -ser impotente de algo-, como no tener la posibilidad de controlar la propia potencia.

El ámbito pedagógico parece amoldado por motivaciones triunfalistas, pero que ponen en evidencia su flaqueza, y que en poco siguen los principios de una formación ética en valores (Sánchez y López, 2016). Ética es todo aquello que afecta a las personas en cuanto son individualizables (no aisladas), en cuanto a sujetos distributivos dentro de un grupo (Padilla, 2010). La inteligencia emocional puede ofrecer una alternativa al paradigma de destrezas competitivas, que se ha enseñoreado en la pedagogía y permeado todos los niveles. El aula deja de ser un espacio para el saber colaborativo y se transforma en una batalla innecesaria y muchas veces autodestructiva, con una suerte de neodarwinismo intolerante.

Goleman (2000) demuestra que los problemas a los que se enfrenta son serios y deben ser tenidos en cuenta durante todo el proceso educativo. A partir de su estudio se puede concluir que cuestiones como la violencia, la depresión, la destrucción y autodestrucción, que emergen con mucha fuerza y en diversas culturas, deben ser tratados de raíz y solo poder controlarlos va a permitir que pueda emerger una ética duradera, capaz de establecer la índole de las responsabilidades morales (Redonod et ál., 2017).

\subsubsection{La influencia de la paideia griega como pedagogía de las virtudes en Goleman}

Goleman se retrotrae al mundo helénico para encontrar allí la articulación entre el pensamiento racional y la buena gestión de las emociones. Puede considerarse 
siguiendo a Jaeger (2000) que la pedagogía encuentra sus raíces en la paideia griega, en donde la meta era formar ética y estéticamente a los discípulos. La kalokagathia (kalos: bello y agathos: bueno) conformaban un horizonte armonioso para la formación virtuosa del ciudadano.

En ese proceso de pretender superar el modelo de una inteligencia por coeficiente intelectual y que agónicamente se desarrolla y se hiere, Goleman recorre el camino helénico de una ética fundada en un concepto de buena vida orientada hacia la felicidad, es decir la eudaimonia socrática, y la ética de las virtudes aristotélica. El autor recurre a la mayéutica, que parte del conócete a ti mismo, para recién ir a la realidad exterior, y todo ello en una forma inteligente, recuperando así la razón tareas de buena gestión de emociones y sentimientos. El autor insiste a su vez en el autoconocimiento propio de la mayéutica socrática, como mecanismo para desarrollar una moral de virtudes, que nos acercaría además a la meta humana por excelencia que es la felicidad.

Quisiera imaginar que, algún día, la educación incluirá en su programa de estudios la enseñanza de habilidades tan esencialmente humanas como el autoconocimiento, el autocontrol, la empatía y el arte de escuchar, resolver conflictos y colaborar con los demás. En su Ética a Nicómaco. Aristóteles realiza una indagación filosófica sobre la virtud, el carácter y la felicidad, desafiándonos a gobernar inteligentemente nuestra vida emocional." (Goleman, 2000, pp. 10-11)

A diferencia del tiempo helénico, Goleman cuenta, además, con evidencia científica acerca de mecanismos neuronales, que comienzan a poder medir reacciones como la empatía, el rechazo, entre otros.

La inteligencia como buena gestora de las emociones en el paradigma de Goleman

Goleman insiste en poder ser conscientes de las propias emociones y sentimientos, en lugar de negarlos. Eso permitiría que ocurra lo contrario de cuando se niegan. La buena gestión de ellos solo es posible cuando se las conoce y aceptan. Y por otra parte permite comprender mejor, y de alguna manera relativizar, las emociones y los sentimientos de los demás. La inteligencia emocional es aquella a partir de la cual sabemos hacer una gestión adecuada de nuestras emociones impulsos sensibles que de pronto perjudican a nosotros a los demás o al medio ambiente y que en definitiva no tienen ninguna virtud ni beneficio entonces la inteligencia emocional que combina dos fuentes que se nos aparece sobretodo clásicamente disímiles como es la inteligencia y la emoción Goleman las fusionan en un intento demostrar que la llamada intelectualidad como la comprendía ese modelo imperialista de alguna manera excluyente lo mostraba lo trata de mostrar la inteligencia emocional permitiría justamente que la inteligencia la sabiduría pueda desarrollarse en plenitud y no sea arrastrada por las malas emociones y en ese sentido tanto Platón como Aristóteles coincidirían.

Con Goleman vamos un poco más lejos y es a través de las emociones, es decir, a través de la empatía que logramos conectarnos con el otro y vivenciar la necesidad de una ética. En Goleman hay un proceso doble: la emoción conduce a la racionalidad y no meramente la racionalidad es la que somete a las emociones. 
En una etapa inicial, propia de la formación educativa, la propuesta de Goleman deriva de la empatía el altruismo. De ese modo se llegaría a una ética personal:

...la raíz del altruismo radica en la empatía, en la habilidad para comprender las emociones de los demás y es por ello por lo que la falta de sensibilidad hacia las necesidades o la desesperación ajenas es una muestra patente de falta de consideración. Y si existen dos actitudes morales que nuestro tiempo necesita con urgencia son el autocontrol y el altruismo. (Goleman, 2000, pp. 8-9)

Puede afirmarse que ese proceso socrático de introspección es lo que nos va a permitir mejor "la comprensión de los sentimientos de los demás". (Goleman, 2000 , p. 114). Sin embargo, quedaría por demostrar en Goleman si el sentimiento de empatía es un factor necesario para la ética, o si puede o debe generarse una ética aún en el caso que no haya empatía.

Hay una suerte de empatía, la ética surge como una forma de racionalidad emocional una percepción del dolor del otro, una injusta situación en la cual podemos considerar se encuentra el otro para después volver hacia nosotros mismos y de alguna manera metafóricamente sentir el dolor en nosotros mismos.

\subsubsection{El telos de la felicidad en Sócrates y el desequilibrio de la racionalidad}

Lo bueno y lo bello se explica en términos estrictamente racionales. Y si es así, que se entiende por razón. En el renacimiento, en el caso de Spinoza no hay una distancia entre la percepción y la razón, en su todo es en dios, ese pan(en)teísmo, supera en complejidad y belleza el sistema cartesiano. Es convincente este universo construido místicamente, probablemente no. En el mundo renacentista en que se fusionaba tan espontáneamente la belleza con la metafísica -en su sentido literal- hablar de una IE probablemente podría haber sido fácilmente comprensible, pero no para derivar alguna ventaja o saber practico. Simplemente, para contemplar la belleza armónica del universo en su sentido más profundo.

En el siglo $X X$ lo que se ha producido es un desequilibrio, una disociación entre la inteligencia como un elemento discursivo y lo emocional como algo autónomo que nos mueve disociadamente. Esa dimensión que procura rescatar Goleman, puede y debe encontrarse en otros autores que lo preceden de modo que haya una continuidad. La superación del homo calculador, interesado, parcializa lo humano a su provecho, lo segrega, finalmente puede llegar a alienarlo.

Extrapolando el concepto de IE podemos afirmar que este concepto ha estado presente a lo largo de la historia, destacándose el renacimiento y el siglo de Pericles. Lo que se echa de menos en el caso de la propuesta de Goleman es el tratamiento sistemático de lo que se ha dado en llamar racionalidad práctica 


\subsubsection{La ética como un derivado de la empatía en Goleman}

Por último con empatía vamos a nombrar ese fenómeno tan querido y tan humano en el que es con el otro. Hay una suerte de empatía, la ética surge como una forma de racionalidad emocional una percepción del dolor del otro, una injusta situación en la cual podemos considerar se encuentra el otro para después volver hacia nosotros mismos y de alguna manera metafóricamente sentir el dolor en nosotros mismos. Las virtudes afianzan la personalidad y consiguen la libertad de los individuos en un plano real (Gallego-Jiménez y Vidal-Raméntol, 2018).

La empatía nos introduce en el camino de la humanidad. De un modo a veces ambiguo o equivoco, pero en definitiva siempre iluminador que nos hace patente nuestra responsabilidad moral única e insustituible. El siglo XXI se ha convertido en un llamado moral, lo cual ha colmado la vida cotidiana. ¿Cómo combinar lo individual y lo universal en la pedagogía? El trabajo se dedica a establecer un puente transdisciplinario entre el paradigma psicológico de Goleman llamado IE y la filosofía práctica de Karl-Otto Apel de una ética de la responsabilidad solidaria.

\subsubsection{Limitaciones de la propuesta de la inteligencia emocional de Goleman}

El libro de Goleman que lo ha llevado a su popularidad dentro y fuera de EEUU es la Inteligencia Emocional. Los ejemplos en los que basa sus estudios y conclusiones son propios de la cultura estadounidense, lo cual a veces corrobora con ejemplos paralelos, generalmente en otros países afines.

Llama la atención desde una perspectiva diferente la forma en que el autor describe locales traumas derivados de situaciones de pobreza relativa. Si se considera otras poblaciones donde la pobreza se encuentra generalizada, la misma no se vive como una situación de exclusión social, pero sí persisten los problemas propios de la carencia material.

Por otra parte, desde una visión ampliada que más de $1400 \mathrm{M}$ de personas viven en el mundo en pobreza y $800 \mathrm{M}$ en pobreza extrema de lo cual no se considera siquiera un mínimo de empatía ni por el autor ni por los casos tratados. ¿Qué ocurre si aquí no hay empatía? Se puede estimular la empatía. No se trata de algo mecánico, puede ser espontaneo, pero no hay garantía de un proceso causal. En este caso la ética kantiana nos muestra un camino fiable.

Si la inteligencia emocional significa la buena gestión de nuestras emociones, y eso teniendo en cuenta los valores, puede acercarse a la templanza.

\subsection{La ética de la responsabilidad solidaria del filósofo Karl-Otto Apel}

En tanto los nutrientes de las propuestas del psicólogo Goleman se encuentran en la filosofía, en particular la aristotélica, vamos a recurrir directamente a fuentes de pensamiento que aspiran ser de libertad y universalidad, y adoptar así una perspectiva filosófica del tema. Aristóteles y a quienes han recorrido un camino 
filosófico de fuentes compartidas, para luego comparar sistemáticamente sus teorías.

En lo siguiente consideramos entonces cómo está propuesta de empatía y ética en Goleman va a encontrarse similarmente en los antecedentes filosóficos griegos por una parte tenemos el ideal griego de belleza y bondad sistemáticamente considerados en la fórmula "kalos kai agathos". Jaeger en su libro La paideia (2000) se ocupa de la educación en el mundo griego: la ética es estética y en ese marco las virtudes que Aristóteles sistematiza tienen una realización plena positiva y posible por el género humano.

\subsubsection{Una ética universal kantiana desde la intersubjetividad}

Las formas complejas de comprender la racionalidad las encontramos exhaustivamente tratadas en la trilogía de I Kant. Estudiar el caso de la ética y la estética en la filosofía donde la inteligencia calculadora cede protagonismo recibido.

La ética de la responsabilidad solidaria es una respuesta a los problemas globales, desde una dimensión ética universal emanada del repensamiento de teorías diversas de la ética alemana luego de asumir los horrores del Holocausto y comprender los problemas que se han exasperado durante la guerra fría y las disparidades regionales y los desastres medioambientales. La reflexión sobre lo acontecido en la II Guerra Mundial es retomada por el filósofo Karl-Otto Apel, quien supera la alternativa de Max Weber de una ética de la intención al modo kantiano y la propia de una ética de la responsabilidad, la cual pone su foco en las consecuencias.

La ética no queda meramente librada a lo contingente de los hechos, sino que la acción moral incluye la preocupación por lo que ocurra allí, sin supeditarlo a eso en la versión renovada de Apel. Frente a la disyuntiva Kant versus Weber, la propuesta superadora de la misma humaniza la segunda opción, la libera de la posible justificación de medios por fines, y la torna solidaria, desde una perspectiva global, logrando conservar la universalidad ética kantiana, que cristalizaba la concepción inalienable de dignidad humana.

En ello también retornamos a la ética aristotélica de las virtudes, que no cae en un despropósito, donde principios son disociados de la realidad. No queda desfasada de una realidad que los podría convertir en un efecto contrario al de la intención originaria. Entonces por una parte precisamos tener fines absolutos buenos, que puedan ser de alguna manera también considerados por el individuo. Por otra parte, evaluar críticamente la metodología para que su acción lleve al fin deseado y no termine siendo contraproductivo.

\subsubsection{La solidaridad sin fronteras como condición necesaria de la ética y en complementariedad con el paradigma de Goleman}

Repensar la mayéutica de Sócrates o la Ética a Nicómaco de Aristóteles, desde variadas disciplinas como son la psicología, la filosofía y la pedagogía, muestran la vigencia de una ética de la felicidad basada en la formación en las virtudes del 
hombre bueno, y facilitan un enfoque transdisciplinario y universal para entender su vigencia y por otra parte para hacer frente a desafíos comunes de la humanidad. Goleman por su parte ve en las virtudes griegas ese horizonte fructífero en donde se deja ver esas emociones guiadas por una educación correcta.

Apel recurre al bellísimo concepto de solidaridad, el cual no se limite a un grupo o comunidad o país, sino que se eleva a la macroesfera, a la recuperación de la humanidad toda, sufriente intra e internacionalmente.

El buen obrar es esencial a la ética, y así una ética universal y realizable que pone como su pilar la dignidad humana a nivel planetario. Es decir, se recupera la dimensión de la acción buena, del obrar bien teniendo en cuenta al otro, siempre portador de dignidad humana. Con esta propuesta Apel logra superar la alternativa weberiana, retomando eso si la importancia el impacto global necesario de la misma.

\subsection{La educación universal como un derecho humano reconocido por la comunidad internacional}

Por cierto, la educación es un proceso complejo que está llamado a la formación de la persona, en particular en valores, en el sentido de lograr virtudes al modo griego. La fusión de una belleza y bondad esenciales, lo que la paideia daba en nombrar kalokagathia (kalos y agathos). El resultado es la persona noble, que comprende el mundo y la humanidad, que naturalmente siente al otro desde la empatía, y el otro es un universal, que de alguna manera contiene la comunidad de vida y las generaciones futuras, desde sí mismo.

Cuando pensamos en dicha pedagogía estamos viendo al ser humano en su biografía, que va nutriéndose en una memoria histórica.

Sin una educación de elementos esenciales no logramos que se realice lo mejor del ser humano, y entonces el ser humano queda a mitad de camino, en situación de poca armonía con su entorno y cayendo una y otra vez en conflictos poco o mal resueltos.

La educación de un ser humano es el lugar convergente donde han participado sus formadores, en particular sus padres o quienes asuman ese papel.

Luego el círculo familiar más extenso, las amistades y gente de bien del entorno, para concluir en terreno institucional en donde los maestros están llamados a asumir un rol magnifico en la inspiración y esclarecimiento de esa persona. La sensación de satisfacción o insatisfacción de las personas supondrá la generación de unas emociones positivas o negativas que, dependiendo de su nivel de inteligencia emocional, provocarán un estado de bienestar, frustración, felicidad o tristeza, por haber elegido ese servicio/producto (Barrientos, 2019). 


\subsubsection{La educación para la libertad desde la UNESCO}

La UNESCO ya había redimensionado el concepto de solidaridad, dando los atributos de intelectual y moral a la vez, probablemente partiendo de la clasificación clásica de virtudes intelectuales y morales.

En su Acta Constitucional de 1945 se pone a la solidaridad como condición necesaria para una paz duradera. Con ello no queda lugar a la ambigüedad, esa solidaridad tiene que ser de todos y para todos, con todos los recursos que tengamos, sea del ámbito académico como personal. Toda la ciencia y las humanidades deben quedar a su servicio. Una solidaridad es moral en un sentido abarcador, que incluya todo lo demás de lo humano, reforzado por los valores del científico, del humanista y del artista, que refuerzan ese gesto noble de humanidad.

La educación como una práctica de la libertad, ideal ahora enarbolado universalmente por la UNESCO encuentra raíces también en el mundo latinoamericano con Paulo Freire, entre otros.

\subsubsection{La importancia de la educación universal y la Convención de los Derechos del Niño para la educación para el siglo XXI}

Ha debido transcurrir la historia para corroborar que ese ideal puede extenderse a toda la ciudadanía, y también a la ciudadanía global. UNESCO ha logrado a través de sus programas interculturales e intercontinentales promover una educación incluyente. "Educación para todos" (education for all) es el lema preponderante al concebir hoy la educación. $Y$ todo ello porque hoy puede afirmarse a la educación como uno de los derechos humanos que merece cada uno.

La educación es un derecho universal, tal como lo enuncia la Convención de los Derechos del Niño (1989) -ratificado por todos los países del mundo a excepción de Estados Unidos- por lo cual se habla de educación universal. Para ello debemos reflexionar que formato se debe asumir para que ello no sea meramente una expresión de deseo, sino que se encarne en los programas educativos.

Entonces, por un lado, la universalidad se encuentra con la educación en tanto se exige que abarque a todos los niños y jóvenes del mundo. Por otra parte, esa universalidad se cristaliza en su contenido. Se percibe que esa universalidad debe convertirse en parte de la materia de aprendizaje. La empatía no debe quedar limitada a una suerte de zona de confort, sino expandirse sin fronteras.

\subsubsection{Una visión ampliada e intercultural sobre la inteligencia emocional de Goleman}

¿Cómo se combina lo individual y lo universal en la pedagogía? Más inteligencia emocional y ética de la responsabilidad solidaridad solidaria para los tiempos actuales. 
¿Cómo recuperar una pedagogía humanista, tras lo curricular que se orientaba a destrezas competitivamente? Debe haber un descubrimiento ético del otro. ¿Quién es el otro en el aula pedagógica?

El impacto que la inteligencia emocional ha tenido sobre la educación de menores, no solo en EEUU sino en otras regiones, es destacable. Su propuesta ha tenido una aportación única para la formación de la persona y la sociedad, y ese objetivo esta compartido con el proyecto humanístico de la ética y la educación, llegando incluso a propuestas como la de las "organizaciones emocionalmente inteligentes" (del Henar Sánchez, 2016) sobre la base de que desde las estructuras más pequeñas hasta las más complejas requieren un mínimo de reglas claras e inclusivas para su funcionamiento y desarrollo (Ganga-Contreras et ál., 2018).

¿Cómo se educa, qué se educa, para qué se educa? ¿De qué modo esa inteligencia emocional recoloca las metas del modelo educativo actual? Que otras guías de la educación, en particular la filosofía y la pedagogía misma, habían llegado a resultados similares, que Goleman extrae de sus experimentaciones psicológicas.

Una política de discriminación y de exclusión si bien el mundo griego arrastra un concepto elitista y por eso mismo excluyente por otra parte sienta las bases de un concepto universal para pensar la acción humana en el marco de la ética del bien por supuesto a nuestros ojos se nos aparecen los grandes tragedias de la esclavitud de la opresión del otro en parcialmente pero más allá de eso hoy podemos rescatar todas ese es el legado que encontramos que hemos recibido de los griegos hacia una concepción universal una comprensión Universal de los Derechos Humanos las virtudes griegas son así capacidades puestas en práctica comportamientos humanos en armonía con los demás y nosotros mismos y que se van a un cumplimiento libre y responsable de la persona con esto quedan descartadas muchas de las consecuencias o al menos aplicaciones de esa inteligencia instrumental deambulo así que Goleman crítica ya la cual opone el concepto este de la inteligencia emocional

\subsubsection{Anexo: Una referencia al mundo ibérico y latinoamericano}

Las propuestas de Goleman se encuentran ya desarrolladas en algunas teorías y prácticas educativas en la región hispanohablante como la de la Institución Libre de Enseñanza (ILE). Pero es cierto, muchas veces censuradas y desestimuladas. Actualmente se avanza en el mundo ibérico y latinoamericano siguiendo las propuestas de Goleman. Se redescubre la enseñanza de Sócrates «conócete a ti mismo" — darse cuenta de los propios sentimientos en el mismo momento en que éstos tienen lugar - constituye e la piedra angular de la inteligencia emocional (Goleman, 2000, p. 58).

Se puede constatar la buena coincidencia entre el trayecto histórico que ha tenido la tradición filosófica en España a través de la ILE como caso más saliente, con lo que hoy surge como propuesta positiva de la inteligencia emocional, aunque sin usar ese término. El fin de mostrar esta similitud entre ambas tiene un sentido, no solo por cuestiones históricas, sino también de reforzar las tradiciones buenas y dar un continuum a un proceso que se lo merece. 
La discontinuidad histórica dada por la persecución del pensamiento libre, del educar desde la libertad como bien enfatiza el filósofo Emilio Lledó con respecto a las prácticas de la década del 1930 nos invita a retomar una tradición que es propia. A veces se piensa que hay que importar prácticas pedagógicas para dar solución a demandas pedagógicas que se consideran insatisfechas. El hecho de que la IE se imponga y merecidamente como un enfoque exitoso en el tratamiento de traumas (Salcido y Urías, 2016) y de enfermedades de reeducación puede y debe empalmarse con las practicas anteriormente existentes de una pedagogía y filosofía en al menos España que maximizaba el desarrollo de las virtudes y talentos desde la educación.

La ILE tuvo como hijos a Unamuno, Machado, Dalí, Buñuel, Zambrano, Lledó y tanto otros, y todos ellos a su modo y en el área de humanidades y arte encarnaron formas plenas de libertad y autorrealización, y de inteligencia emocional. La propuesta de Goleman puede empalmarse en esa tradición pedagógica y humanista española, y sería una pena que se haga omisión de una memoria histórica de una educación en valores, muy desarrollada en España. El daño de la guerra civil y de la posterior dictadura interminable han desembocado en el haber truncado estos grandes avances para la época como lo fue la ILE.

Así también el beber en las fuentes del pensamiento griego estaba a la base para la formación del individuo, no tanto por combatir la hegemonía de una racionalidad calculadora, sino más bien como el camino pleno para una paideia, al modo como lo muestra Lledó o en la tradición alemana Jaeger.

Lo humano se encontraba en el centro del proceso pedagógico. El cultivo de las virtudes, el educar a través de la empatía se encontraban en el centro del aula de la ILE, que por cierto no era un aula tradición, sino que la práctica pedagógica se trasladó al espacio público compartido. Las clases se daban en las calles a través del teatro, a través de vivenciar en la ruralidad la perfección estética de un museo que llegaba a todos los rincones de España, a hombres y mujeres por igual, niños y niñas.

Repensar o reinventar la pedagogía, la formación del individuo o su reeducación, se nutre de una memoria histórica como de avances facilitados por la psicológica de Goleman. La inteligencia emocional invita también a una memoria histórica en este caso pedagógica. Recuperar esas prácticas que fueron castigadas y luego prohibidas por el franquismo es una forma también de reeducar al modo de la inteligencia emocional.

Nos vemos allí con sorpresa que descubrimos una educación de avanzada coincidente con muchas de las propuestas educativas de la inteligencia emocional. La tradición filosófica en la que ambos se nutren inaugura otra forma de pensar la ILE. Desde la IE vemos que la ILE es el paradigma pionero de la misma, y que recuperarla para ponerla en el lugar merecido hoy desde una memoria histórica sería un tributo fructífero que España se merece. Un trayecto paralelo al de Goleman en el tema de ética y empatía considerando las raíces filosóficas griegas y también pedagógicas propias de la paideia y la teoría de las virtudes de Aristóteles en parte 
por el considerada como una de las fuentes de inspiración y por otra parte realizar un trayecto contemporáneo junto a los pensadores humanistas españoles a partir del siglo XX donde se recurre a las fuentes griegas y se las adapta filosóficamente a la pedagogía contemporánea por otra parte y viendo que en el mundo español tenemos aspectos enormemente creativos e innovadores en el siglo 20 recurriremos a considerar la Institución Libre de Enseñanza en los tiempos de la Primera y Segunda República para ver así como se manifiesta implícitamente un tratamiento adecuado de las capacidades intelectuales sabías o cognitivas de la persona humana independientemente de lo que ha sido este paradigma desgastante de una racionalidad instrumental funcional pero que no logra amplitud de vuelo.

\section{CONCLUSIONES}

Cuando Goleman nos invitaba a repensar el paradigma imperante del coeficiente intelectual, que guía la educación y el mercado laboral en el planeta, a la luz de lo que él llama inteligencia emocional, lograba liberarnos de mecanismos extremadamente competitivos, que ponen en peligro el bienestar humano. A partir de ahí hemos visto que la ética que Goleman derivaba desde la empatía y que nutría de la filosofía griega, en particular Sócrates y Aristóteles, estimula parcialmente una aptitud ética, pero no nos garantiza una perspectiva ética global, que vaya más allá de lo directamente vivido empáticamente.

La segunda fuente de nuestra investigación ha ido en busca de una ética que se ocupe universalmente de la humanidad. Se ha considerado la ética de la responsabilidad solidaria del filósofo Karl-Otto Apel heredero a la vez que de la filosofía griega, también de la alemana, de Kant y Max Weber. Apel logra fusionar posturas inicialmente antagónicas de estos dos autores, para completar su sistema que parte de una ética discursiva, que se sostiene desde intersubjetividad.

El tercer componente para lograr una pedagogía fortalecida se encuentra aquí en la extraordinaria normativa que se viene desarrollando desde el fin del Holocausto. La comunidad internacional a partir de 1945 da muestras de gran creatividad y vitalidad para desarrollar un sistema de derechos humanos de alcance universal, en donde la educación es derecho reconocido y medio de realización. Ese anclaje en lo legal y lo histórico hace posible un marco adecuado para una pedagogía de personas libres y responsables en un mundo con desafíos múltiples que van de lo personal a lo comunitario y mundial.

La inteligencia emocional, la ética de la responsabilidad solidaria y la universalidad de los derechos humanos -en particular de los niños- pueden integrarse en el aula como un proyecto compartido. Los derechos humanos, y no solo el derecho a la educación, se convierten en parte constitutiva de la labor pedagógica. Emerge como tema principal para la educación la faceta universal del otro que comienza a desplegarse como tema imprescindible en el aula. Los nuevos desafíos del siglo XXI como la COVID19, la pobreza extrema y el cambio climático precisan nuestra ocupación y preocupación ética solidariamente. 


\section{BIBLIOGRAFÍA:}

Abanades Sánchez, M. (2016). Nuevo perfil del docente en la educación superior: formación, competencias y emociones. Opción, 32(Especial № 8), 17-37.

Arroyo Almaraz, I. (2013). El valor de las ideas para el cambio social: Publicidad social, Biopolítica y Neuroética. CIC. Cuadernos De Información $Y$ Comunicación, 18, 223-241. https://doi.org/10.5209/rev CIYC.2013.v18.41819

Apel, K. O. (1986). Estudios éticos. Editorial Alfa.

Apel, K. O. (1991). Teoría de la verdad y ética del discurso. Ediciones Paidós lbérica (original en alemán 1987).

Asamblea General de las Naciones Unidas (1989). Convención de los Derechos del Niño. Resolución 44/25 adoptada por la Asamblea General el 20 de noviembre de 1989.

Asamblea General de las Naciones Unidas (2015). Transformar nuestro mundo: la Agenda 2030 para el Desarrollo Sostenible. Resolución A/res/70/1 aprobada por la Asamblea General el 25 de septiembre de 2015.

Barrientos-Báez, A., Barquero-Cabrero, M., y Rodríguez-Terceño, J. (2019). La educación emocional como contenido transversal para una nueva política educativa: el caso del grado de turismo. Revista Utopía y Praxis Latinoamericana. 24(4), 147-165

Bustos Martínez, L., De Santiago Ortega, P. P., Martínez Miró, M. Ángel, \& Rengifo Hidalgo, M. S. (2019). Discursos de odio: una epidemia que se propaga en la red. Estado de la cuestión sobre el racismo y la xenofobia en las redes sociales. Mediaciones Sociales, 18, 25-42. https://doi.org/10.5209/meso.64527

Carreras Álvarez, M. V. (2014). La docencia virtual en la Universidad de Sevilla: descripción de las herramientas online. Historia Y Comunicación Social, 18, 4960. DOI: https://doi.org/10.5209/rev HICS.2013.v18.43947

Catalina-García, B., López de Ayala-López, M. C., \& Martínez Pastor, E. (2019). Usos comunicativos de las nuevas tecnologías entre los menores. Percepción de sus profesores sobre oportunidades y riesgos digitales. Mediaciones Sociales, 18, 43-57. DOI: https://doi.org/10.5209/meso.64311

del Henar Sánchez Cobarro, P. (2016). Organizaciones emocionalmente inteligentes. Revista de Ciencias de la Comunicación e Información, 21(1), 19-33. DOI: http://doi.org/10.35742/rcci.2016.21(1).19-33

Fernández-Beltrán, F., García-Marzá, M., Sanahuja Sanahuja, R., Andrés Martínez, A. y Barberá Forcadell, S. (2017). La gestión de la comunicación para el impulso de la Investigación e Innovación Responsables: propuesta de protocolo desde la ética dialógica. Revista Latina de Comunicación Social, 72, 1040-1062. DOI: http://doi.org/10.4185/RLCS-2017-1207 
Gallego-Jiménez, G. y Vidal-Raméntol, S. (2018). El valor de la virtud en la educación. Revista de Comunicación VIVAT Academia, 145, 23-29. DOI: https://doi.org/10.15178/va.2018.145.23-39

Ganga-Contreras, F., Dra. Suárez-Amaya, W. Alarcón, N. (2018). Liderazgo en la gobernanza de las universidades: aprendiendo ciertas lecciones desde la etología. Revista Inclusiones VOL. 5(Especial) Abril/Junio

Ganga Contreras, F. y Luna Negrete, G. (2018). Capital Humano (CH): Estudio descriptivo de las publicaciones en la base de datos Scientific Electronic Library Online (SciELO). Revista Inlcusiones, 5(4), 146-166.

Goleman, D. (2000). Inteligencia emocional. Por qué es más importante que el coeficiente intelectual. Editorial Vergara (original en inglés 1995).

Goucha, M. (coord.) (2007). Philosophy: A School of Freedom. Teaching Philosophy and Learning to Philosophize: Status and Prospect. UNESCO.

Jaeger, W. (2000). Paideia: Los ideales de la cultura griega. Fondo de Cultura Económico (original en alemán 1939).

Jaspers, K. (1984). La filosofía desde el punto de vista de la existencia. FCE (original en alemán 1949).

Lledó, E. (2020 a). En torno al “bienser”. Antología. Junta de Andalucía.

Lledó, E. (2020 b). Ojalá el virus nos haga salir de la caverna, la oscuridad y las sombras. El País, 29/3/20.

Martínez-Otero Pérez, V. y García-Lago lbáñez, V. (2013). Aspectos conceptuales sobre la inteligencia afectiva y su fomento a través de la lectura en la escuela. Revista de Comunicación de la SEECI, 30, 106-120.

Niño González, J. I., García García, E. y Caldevilla Domínguez, D. (2017). Inteligencia emocional y educación universitaria: una aproximación. Revista de Comunicación de la SEECI, 43, 15-27. DOI: http://dx.doi.org/10.15198/seeci.2017.43.15-27

Padilla Castillo, G. (2010). Los conflictos entre Ética, Moral y Política en la Comunicación Institucional y Periodística de las series de televisión Sí, Ministro y Sí, Primer Ministro. CIC. Cuadernos De Información Y Comunicación, 15, 165185. Recuperado https://revistas.ucm.es/index.php/CIYC/article/view/CIYC1010110165A

Parra-López, E., Barrientos-Báez, A. y Martínez-González, J. A. (2020). La transformación digital del turismo. Revista de Occidente, 464. 52-66. ISSN: 00348635. 
Redondo, M., Sánchez-García, P. y Etura, D. (2017). Investigación de la enseñanza ética de los periodistas en España. Análisis bibliométrico y prescripciones formativas aplicadas (2005-2015). Revista Latina de Comunicación Social, 72, 235-252. DOI: http://dx.doi.org/10.4185/RLCS-2017-1163

Salcido Cibrián, L. J. y Urías Aguirre, K. M. (2016). Educación emocional en casos de violencia y victimización escolar: propuesta de intervención. Opción, 32(Especial №12), 2088-2102.

Sánchez Marín, F. J., y López Mondéjar, L. M. (2016). La relación educativa desde la perspectiva ética del desempeño docente. Revista de Ciencias de la Comunicación e Información, 21(2), 45-65. DOI: http://doi.org/10.35742/rcci.2016.21(2).45-65

Suberviola Ovejas, I. (2012). Competencia emocional y rendimiento académico en el alumnado universitario. Revista de comunicación VIVAT Academia, XIV(117E), 117. DOI: https://doi.org/10.15178/va.2011.117E.1-17

Teruel Rodríguez, L. (2014). Construcción colectiva del conocimiento a través de la web social y motivación del alumnado: Proyecto de innovación docente aplicado al Grado en Comunicación. Historia Y Comunicación Social, 18, 523-534. DOI: https://doi.org/10.5209/rev HICS.2013.v18.44258

\section{AUTORA:}

\section{María del Carmen Patricia Morales}

Estudió filosofía en la Universidad de Buenos Aires y en la Universidad Goethe de Frankfurt. Obtuvo su doctorado en 1997 en la Universidad de Buenos Aires con su tesis Derechos humanos y ética de la responsabilidad solidaria. Es profesora visitante en la Universidad de Lovaina (Lovaina) para seminarios sobre pensamiento español y latinoamericano, e investigadora en temas filosóficos e interdisciplinarios de ética, derechos humanos, desarrollo sostenible y diálogo intercultural. Ha recibido la beca Giner de los Ríos en 2018 en la Universidad de Alcalá de Henares, y también profesora Erasmus en 2017 y 2019 en Alcalá de Henares y en 2018 en la UAM. Ella participa en la Cátedra UNESCO de Seguridad Humana en la UPB, Argentina y fue coordinadora de la Cátedra UNESCO de Paz Sostenible de la Universidad de Lovaina. En la Universidad de Tilburgo (1998-2003), se involucró en conferencias internacionales, sobre ética, derechos humanos y la Carta de la Tierra. Es editora de Pueblos Indígenas, Derechos Humanos e Interdependencia Global (2001). Colabora con la UNESCO, UNAOC y miembros de varias universidades y ONG de diferentes países, siendo miembro activo de Mundus Maris y de Terra Curanda donde realiza trabajos académicos y periodísticos de radio para temas de derechos humanos, medio ambiente y arte.

patricia.morales@kuleuven.be

Orcid ID: https://orcid.org/0000-0003-2979-1582

Google Scholar: https://scholar.google.com/citations?hl=es\&user=xmbgwucAAAAJ

Academia.edu: https://kuleuven.academia.edu/MariadelCarmenPatriciaMorales 